\title{
FDA Approvals of Medical Devices Under the De Novo Automatic Class 3 Regulations: An Opinion
}

\author{
Michael AB Naafs* \\ Dutch Internist, Endocrinologist, Health Consultant at Naafs, International Health Consultancy, Rhodoslaan Netherlands
}

Received: 制 August 18, 2018; Published: 眥 August 22, 2018

*Corresponding author: Michael AB Naafs, Dutch Internist-Endocrinologist, Health Consultant at Naafs, International Health Consultancy, Rhodoslaan 20,7577KN, Oldenzaal, The Netherlands

Abstract

The new FDA class 3 automatic medical devices regulations were recently introduced to meet criticism of all sides on the past regulations. An evolving Essure scandal accelerated the launching of this ambitious new plan. Unfortunately, the last FDA approvals, a transcranial magnetic deep brain stimulation system (TMS) and a vaginal hormonal contraceptive ring, don't reflect this new wave.

\section{Introduction}

Recently, The Brainsway Deep Transcranial Magnetic Stimulation System received FDA marketing clearance for the treatment of obsessive compulsive disorder [OCD]-[1]. OCD is commonly treated with medication and/or psychotherapy but some patients continue to experience symptoms. Transcranial magnetic stimulation [TMS] uses magnetic fields to stimulate nerve cells in the brain. The FDA previously permitted marketing of TMS to treat major depressive disorder in 2008 and for pain associated with certain migraine headaches in 2013 [2,3]. The Brainsway device was reviewed under the FDA de novo premarket review pathway intended for some low- to moderate risk devices that are novel and for which there is no legally marketed predicate device to which the device can claim substantial equivalence [4].

Another recently approved device under this new automatic class 3 designation is a self-administered contraceptive vaginal system approved for up to 1 year of use [5]. There has been a lot of criticism on the FDA's medical device oversight facing criticism from all sides. Some have accused the agency of approving devices on the basis of weak evidence and surrogate endpoints, with cardiovascular devices making up the largest class of recent FDA recalls. Others have complained that delays to device approvals are putting patients at risk and deterring innovation [6].

FDA has announced the de novo class 3 regulation as a new "action plan" to address concerns throughout the life cycle of medical devices from premarket review through postmarket surveillance, with emphasis on the growing importance of cybersecurity. In a statement issued April 17, FDA Commissioner Scott Gotlieb, MD, announced the release of the Medical Device Safety Action Plan: Protecting Patients, Promoting Public Health [7].
A past medical device approval leading in part to the new regulations is known as the Essure debacle [8]. Essure is a device consisting of two flexible metal coils inserted into the Fallopian tubes that are supposed to cause enough scarring to stop sperm from passing through to fertilize eggs. This device entered the market 16 years ago by Bayer. Since then, over 15.000 patients have filed lawsuits against Bayer and thousands of women have reported complications to the FDA including Fallopian tube perforations, unintended pregnancies, autoimmune symptoms and severe pain and bleeding that have resulted in hysterectomies [8].

A successful social media campaign on Facebook, known as "Essure Problem" was launched by Angie Firmolino. A Netflix documentaire "The Bleeding Edge" premiered at July 27th, 2018. Bayer announced stop selling its controversial birth control device as a business decision on July 20th, 2018 [9]. So, even with a wellorganized campaign against it and thousands of harms brought to the FDA it still took 16 years for it to be taken off the market., and even without the manufacturer or the FDA acknowledging the scope of the device's safety problems.

The approved process of devices has been fraught of loopholes. Nearly $99 \%$ of these devices got on the market without their manufacturers providing adequate clinical data or randomized clinical trials [RCTs]. Only 1 in 10 post-market studies on the safety and efficacy of devices were completed within five years of FDA approval [10].

These 2 new approvals under the new automatic class 3 regulations (1.6) show no substantial changes in safety regulation compared to experiences in the past and offer therefore few hopes in 
the future. The TMS device to treat Obsessive Compulsive Disorder is based on weak evidence gathered from an underpowered randomized, multicenter study in 100 patients, randomized to the Brainsway device or a sham device. Study patients who were receiving pharmacologic therapy for OCD (mainly SSRIs) were maintained at their existing doses throughout the study. Researchers examined the reduction in patient's Yale Brown Obsessive Compulsive Scale (YBOCS) score, a common measure of OCD severity. Results showed that $38 \%$ of patients responded to the Brainsway device versus $11 \%$ of patients who responded to the sham device. Response was defined as $>30 \%$ reduction in the YBOCS score. Headache was the most reported side effect 37 , $5 \%$ the Brainsway group and $35,3 \%$ in the sham group. No serious adverse reactions to the Brainsway device were observed.

The Annovera (segesterone acetate and ethinyl estradiol) vaginal system, Therapeutics MD, is a new combined hormonal contraceptive device to prevent pregnancy. It is a soft, donut shaped, non-biodegradable and flexible silicone vagina ring that can be self-inserted. The vaginal ring is inserted for 3 weeks followed by removal for 1 week. The vaginal ring is supposed to be used up to 1 year after starting its use. The safety and efficacy was evaluated in 3 open-labeled studies involving healthy women aged 18-40. Results showed that Annovera was 97, 3\% effective in preventing pregnancy in 2 pooled studies [ $\mathrm{n}=2111]$. The FDA is requiring post-marketing studies to evaluate the risk of thromboembolism (VTE) and the impact of CYP3A modulating drugs and tampon use on the pharmacokinetics of Annovera. According to the company a post-approval study will be performed to assess the risk of VTE The product has not been evaluated in females with a BMI>29 kg/ square meter. As the JAMA study indicated the chance that these requested post-marketing will be performed within 5 years is $10 \%$ [10], enough time to do harm.

\section{ISSN: 2574-1241}

\section{DOI: 10.26717/BJSTR.2018.08.001623}

Michael AB Naafs. Biomed J Sci \& Tech Res

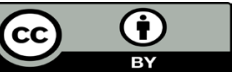

This work is licensed under Creative Commons Attribution 4.0 License

Submission Link: https://biomedres.us/submit-manuscript.php

\section{Conclusion}

The FDA new class 3 automatic medical devices regulations were designed after receiving a lot of criticism in the last 2 decades of all sides and facing the recent Essure scandal. Key elements of this plan are establishing a safety net to detect emerging safety signals, followed by quick and appropriate actions. In addition, streamline and speed-up of postmarket mitigations are a goal. Spurring innovations and advancing medical cybersecurity is another objective, as well as integrating premarket and postmarket offices and responsibilities [4,7]. Unfortunately, this is not yet reflected in some of the last FDA approvals.

\section{References}

1. Han DH (2018) TMS Device Cleared to Treat Obsessive Compulse Disorder.

2. Staring AJ, Tepper SJ, Mamura MJ (2018) A multicenter, prospective, single arm, open label, observational study of sTMS for migraine prevention (ESPOUSE Study). Cephalgia 386: 1038-1048.

3. Grant J (2017) Obsessive-compulsive disorder: Treatment with psychotherapy and pharmacotherapy. Presentation at Psych. Congress 2017:16-21.

4. (2018) Evaluation of Automatic Class in Designation (De Novo)-FDA.

5. Martyn A (2016) After years of criticism FDA tries to step up oversight of medical devices. Consumer Affairs.

6. Han DH (2018) Self-Administered Contracetal Vaginal System Approved For Up To 1 Year Of Use. Endocrinology Advisor.

7. McKeown LA (2018) FDA's 'Medical Device Safety Active Plan' Focuses on Product Life Cycles and Preventing Cyberattacks.

8. Joyce M (2018) Essure's demise isn't an end to medical device safety problems. Health News Review Org.

9. Kaplan S (2018) Bayer Will Stop Selling the Troubled Essure Birth Control Implants. New York Times.

10. Ross J (2015) Strengthening Medical Device Post-Market Safety Surveillance: Editors Note. JAMA Int Med 175(8): 1350-1355.

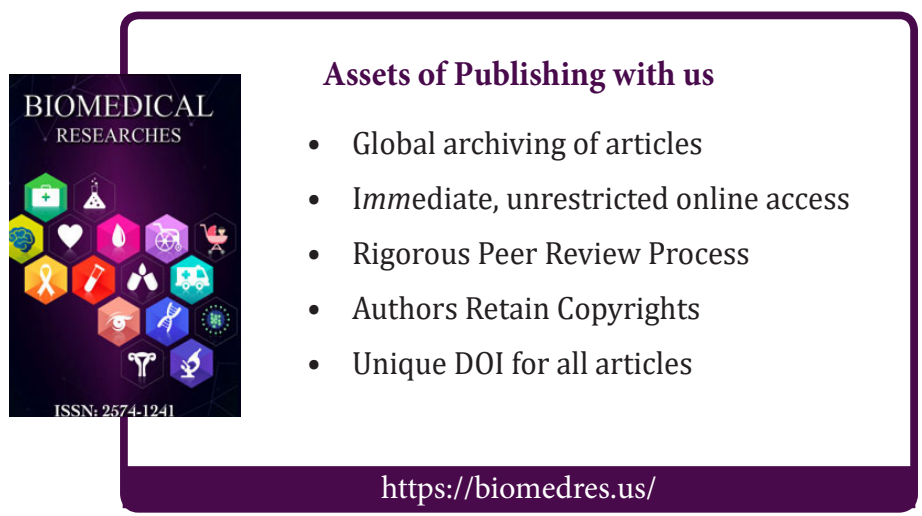

